STUDI

FRANCESI

\section{Studi Francesi}

Rivista quadrimestrale fondata da Franco Simone

188 (LXIII | II) | 2019

Penser/peser le Moyen Âge entre XVe et XVIIe siècle:

parcours de recherche - sous la direction de Maurizio

Busca et Piero Andrea Martina

\title{
Arianna Beatrice Fabbricatore, La Querelle des Pantomimes. Danse, culture et société dans l'Europe des Lumières
}

\section{Paola Martinuzzi}

\section{(2) OpenEdition Journals}

\section{Edizione digitale}

URL: http://journals.openedition.org/studifrancesi/19826

DOI: 10.4000/studifrancesi. 19826

ISSN: 2421-5856

\section{Editore}

Rosenberg \& Sellier

\section{Edizione cartacea}

Data di pubblicazione: 1 août 2019

Paginazione: 359-360

ISSN: 0039-2944

\section{Notizia bibliografica digitale}

Paola Martinuzzi, «Arianna Beatrice Fabbricatore, La Querelle des Pantomimes. Danse, culture et société dans l'Europe des Lumières», Studi Francesi [Online], 188 (LXIII | II) | 2019, online dal 01 février 2020, consultato il 25 janvier 2021. URL: http://journals.openedition.org/studifrancesi/19826 ; DOI: https:// doi.org/10.4000/studifrancesi.19826

Questo documento è stato generato automaticamente il 25 janvier 2021.

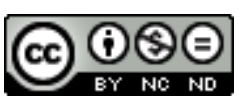

Studi Francesi è distribuita con Licenza Creative Commons Attribuzione - Non commerciale - Non opere derivate 4.0 Internazionale. 


\title{
Arianna Beatrice Fabbricatore, $L a$ Querelle des Pantomimes. Danse, culture et société dans l'Europe des Lumières
}

\author{
Paola Martinuzzi
}

\section{NOTIZIA}

Arianna Beatrice Fabbricatore, La Querelle des Pantomimes. Danse, culture et société dans l'Europe des Lumières, Rennes, Presses Universitaires de Rennes, 2017, 471 pp.

1 Il volume, che si compone di sei capitoli e di una appendice documentaria, ha per oggetto il dibattito settecentesco che vide protagonisti i coreografi Jean-Georges Noverre e Gasparo Angiolini, fra il 1773 e il 1776. La polemica viene ricostruita e analizzata, nel contesto culturale dell'illuminismo lombardo e francese.

In concomitanza con questo dibattito, fa osservare dettagliatamente l'autrice, si stava svolgendo un cammino verso l'autonomia teorica dell'arte dell'attore; esemplare da questo punto di vista è l'opera svolta da Louis Riccoboni e dal figlio François, che valorizzano l'attore in quanto artista. Non a caso la querelle Angiolini/Noverre coinvolge un francese e un italiano. Negli anni centrali del secolo, il mondo musicale e teatrale era stato agitato dalla Querelle des Bouffons che opponeva i sostenitori dell'opera musicale francese, come Rameau, ai difensori della musica italiana, Rousseau in primis. Dopo quegli anni, il clima di rivalità fra le due nazioni sembra dunque estendersi dall'ambito musicale a quello coreografico e coreutico. Due modelli culturali diversi si confrontano, in un secolo che vede l'Italia intenta nel progetto collettivo di costruzione di una identità culturale, molto diversa in questo dalla nazione francese, che si riconosceva nelle sue consolidate istituzioni accademiche. Gli spettacoli hanno in ciò una particolare funzione: contribuiscono a fissare il gusto di una nazione. 
Il saggio dimostra che, nel dialogo acceso fra i due riformatori della danza, si mettono in gioco anche dinamiche sociali e politiche, che vedono il tema dell'integrazione o dell'espulsione della presenza culturale italiana nel territorio francese. Ma l'impegno polemico di Noverre e di Angiolini ha una motivazione più specifica, ovvero l'esigenza di una legittimazione dell'arte della danza, analogamente al processo che ha visto la ricerca di una «dignità culturale» per l'arte attorica, che all'inizio del xviII secolo era ancora radicata nella disciplina retorica e oratoria.

4 La riflessione teorica di Angiolini comincia nel 1761, nei libretti dei balletti creati in collaborazione con lo scrittore Calzabigi e il compositore Gluck. Quella di Noverre si distende nelle ampie Lettres sur la danse la cui prima edizione è del 1760. Il modello estetico di riferimento per il coreografo italiano, evidenzia il saggio che presentiamo, è la poesia e questo motiva Angiolini nella sua ricerca di dare innanzitutto corpo, con la danza e con la pantomima, alle passioni dei personaggi; egli propone l'eloquentia corporis all'interno di una cornice visiva semplice. Il modello del coreografo francese è invece la pittura; tale posizione colloca il pensiero di Noverre accanto all'enciclopedista e teorico della danza Louis de Cahusac, nel solco dell'estetica diderottiana del tableau. L'attenzione ossessiva per la tecnica, per l'insieme scenico, compresi i costumi, giunge in Noverre al gusto per la pompa e la magnificenza.

5 L'analisi dei libretti (o programmi), che parte da una riflessione terminologica, giunge a una teorizzazione di questo specifico genere testuale e si focalizza su due esempi significativi: Didone abbandonata, ballo tragico pantomimo di Angiolini su testo di Metastasio (1772) e Apelle et Campaspe, ballet héroï-pantomime di Noverre con musica di Aspelmayer (1773). Sono segnalate le fonti di questi soggetti e vengono indagate la struttura drammaturgica, musicale e coreografica.

6 Gli «Annexes» contengono alcuni testi significativi e poco noti della polemica. Essi sono la traduzione anonima in francese, conservata all'Opéra di Parigi, del libello di Angiolini (Lettres critiques adressées à M. Noverre), la Introduction au Ballet des Horaces ou petite réponse aux grandes lettres du Sr Angiolini di Noverre (Milano, 1774), l'anonima Lettre d'un des petits oracles de M. Angiolini au Grand Noverre (Milano, 1774) e un testo anonimo e satirico, Le Pacificateur Lombard, conservato negli Archivi Verri (1775). 